\title{
Causal beliefs and attitudes to people
} with schizophrenia

\author{
Trend analysis based on data from two population surveys \\ in Germany
}

MATTHIAS C. ANGERMEYER and HERBERT MATSCHINGER

\begin{abstract}
Background It is a widely shared belief that an increase in mental health literacy will result in an improvement of attitudes towards people with mental illness.
\end{abstract}

Aims To examine how the German public's causal attributions of schizophrenia and their desire for social distance from people with schizophrenia developed over the 1990s.

Method Atrend analysis was carried out using data from two representative population surveys conducted in the Länder constituting the former Federal Republic of Germany in 1990 and 2001.

Results Parallel to an increase in the public's tendency to endorse biological causes, an increase in the desire for social distance from people with schizophrenia was found.

\section{Conclusions The assumption} underlying current anti-stigma programmes that there is a positive relationship between endorsing biological causes and the acceptance of people with mental illness appears to be problematic.

Declaration of interest None. Funding detailed in Acknowledgement.
It is a widely shared belief that an increase in the public's mental health literacy (Jorm, 2000) will result in an improvement of attitudes towards people with mental illness. Most of the current anti-stigma programmes are based on this rationale (Lopez-Ibor, 2002). In particular, promoting biological concepts as a causal explanation for mental disorders is considered to be a promising strategy. The argument is that if the causes of mental disorders were attributed to factors outside the individuals' control, people's reactions to those with mental illness would be less negative. This assumption has not been empirically tested until now. In this study, based on a trend analysis of data from two representative population surveys in Germany, we therefore investigate whether the greater the public's endorsement of biological causes of schizophrenia, the less is its desire for social distance from people with schizophrenia.

\section{METHOD}

In the spring of 1990 a representative survey was conducted in what was then the Federal Republic of Germany among German citizens aged 18 years and older, living in non-institutional settings. The sample was drawn using a three-stage sampling procedure, with sample points (electoral wards) at the first stage, households at the second stage and individuals within the target households at the third stage. Target households within the sample point were determined according to the random route procedure: that is, a street was selected randomly as a starting point from where the interviewer followed a set route through the area (Gabler \& HoffmeyerZlotnik, 1997). Within the target households, the interviewees were selected by means of random digits. A total of 2118 interviews were conducted, reflecting a response rate of $71.9 \%$.

In 2001 a second representative survey was conducted; this time the sampling frame differed, with the sample being drawn from the whole of Germany, the number of interviews conducted in the West and the East reflecting the proportions of the population living in the two parts of the country. Apart from this, the same three-stage sampling procedure was used as in the previous survey. In total, 5025 interviews were conducted (reflecting a response rate of $65.1 \%$ ), 4020 of which were obtained in the States (Länder) representing the former Federal Republic of Germany. The socio-demographic characteristics of both samples are shown in Table 1. For comparison, data from the Official Registry for the total population are also provided; no major difference is apparent.

\section{Interview}

In both surveys a largely identical personal, fully structured interview was conducted. Therefore, no pre-testing was necessary for the second survey. In both surveys, the same vignettes and the same instruments were applied and used for analyses.

\section{Vignettes}

At the beginning of the interview respondents were presented with a vignette of a diagnostically unlabelled psychiatric case history, depicting a case of either schizophrenia or major depressive disorder. The symptoms described in the vignettes fulfilled the criteria of DSM-III-R (American Psychiatric Association, 1987) for the respective disorder. Before the vignettes were used in the survey, each was independently rated by five experts on psychopathology (psychiatrists or psychologists) masked to the actual diagnosis, providing confirmation of the correct diagnosis for each case history. The respondents were randomly allocated to receive one of the two vignettes. In this analysis only data from interviews containing the vignette depicting schizophrenia have been used (1990 survey, $n=511 ; 2001$ survey, $n=1987)$.

\section{Causal attributions}

Respondents' attributions of the cause of the schizophrenic disorder depicted in the vignette were assessed by responses to eight items, with two items each referencing psychosocial stress (life event, stress at work), biological causes (brain disease, heredity), conditions of socialisation (broken home, lack of parental affection) or causes that 
Table I Socio-demographic characteristics of the population samples

\begin{tabular}{|c|c|c|c|c|}
\hline & \multicolumn{2}{|c|}{1990} & \multicolumn{2}{|c|}{2001} \\
\hline & Survey & $\begin{array}{c}\text { Total } \\
\text { population' }\end{array}$ & Survey & $\begin{array}{c}\text { Total } \\
\text { population }\end{array}$ \\
\hline & (\%) & (\%) & (\%) & (\%) \\
\hline \multicolumn{5}{|l|}{ Gender } \\
\hline Male & 45.5 & 48.5 & 43.8 & 48.3 \\
\hline Female & 54.5 & 51.5 & 56.2 & 51.7 \\
\hline \multicolumn{5}{|l|}{ Age, years } \\
\hline $18-25$ & $\mathrm{II} .4$ & 12.3 & 11.8 & 9.8 \\
\hline $26-45$ & 36.4 & 38.0 & 38.7 & 37.8 \\
\hline $46-60$ & 25.0 & 24.2 & 24.1 & 23.8 \\
\hline $61+$ & 27.2 & 25.5 & 25.4 & 29.1 \\
\hline \multicolumn{5}{|l|}{ Educational attainment } \\
\hline Still a student & $0.6^{3}$ & $0.4^{4}$ & $0.3^{3}$ & $0.2^{4}$ \\
\hline No school completed & $3.7^{3}$ & $2.5^{4}$ & $3.8^{3}$ & $2.1^{4}$ \\
\hline Hauptschule ( 9 years of school completed) & $54.7^{3}$ & $55.8^{4}$ & $45.2^{3}$ & $49.1^{4}$ \\
\hline $\begin{array}{l}\text { Realschule/Polytechnische Oberschule } \\
\text { (10 years of school completed) }\end{array}$ & $24.8^{3}$ & $25.8^{4}$ & $32.5^{3}$ & $27.5^{4}$ \\
\hline $\begin{array}{l}\text { Fachhochschulreife/Abitur (technical college of } \\
\text { higher education/A-levels) }\end{array}$ & $16.8^{3}$ & $15.5^{4}$ & $18.1^{3}$ & $21.1^{4}$ \\
\hline \multicolumn{5}{|l|}{ Marital status } \\
\hline Married & 60.9 & 61.2 & 55.2 & 56.5 \\
\hline Divorced & 3.1 & 5.4 & 8.9 & 7.5 \\
\hline Widowed & 14.6 & 10.6 & II.0 & 9.2 \\
\hline Single & 21.4 & 22.8 & 24.8 & 26.8 \\
\hline
\end{tabular}

1. Data from the Federal Statistical Office for the population of the former West Germany aged 18 years and over. 2. Data from the Federal Statistical Office for the population of the whole of Germany aged 18 years and over, for the closest year (2000).

3. For comparison: the data for the population aged 20 years and over from the survey.

4. Data from the Federal Statistical Office for the population aged 20 years and over. No information was available for persons aged $18-20$ years.

individuals could influence themselves (lack of willpower, immoral lifestyle). Using a five-point Likert scale ranging from 'definitely a cause' to 'definitely no cause', respondents were asked to indicate how relevant they considered each potential cause to be.

\section{Social distance}

For the assessment of respondents' desire for social distance we used a scale developed by Link et al (1987), a modified version of the Bogardus Social Distance Scale (Bogardus, 1925). It includes seven items representing the following social relationships: tenant, co-worker, neighbour, member of the same social circle, person one would recommend for a job, in-law and child carer. Using a five-point Likert scale ranging from 'in any case' to 'in no case at all', the respondents could indicate to what extent they would, in the situation presented, accept the person described in the vignette.

\section{Statistical analysis}

To test the effect of time on the two combined response categories, indicating either agreement or disagreement, logit models were estimated with each of the items, assessing people's causal attributions and their desire for social distance. The year 2001 served as the reference category. All effects were controlled for the effect of gender, age and educational attainment. In order to take into account the multistage sampling procedure, the analyses were carried out with SVYLOGIT of STATA version 8 SE (Stata, 2003), using the 510 sample points as primary sampling units. Owing to the large sample sizes, the power of statistical tests was quite high; effect sizes therefore were also calculated.

\section{RESULTS}

\section{Causal beliefs and preference for social distance in 1990}

In 1990 the German public's beliefs about the causes of schizophrenia were quite discrepant from what mental health professionals consider to be of aetiological relevance (Table 2). Psychosocial stress was particularly popular among the public: acute stress (life events) ranked first and chronic stress (stress at work) second. In contrast, biological factors ranked fifth (brain disease) and sixth (hereditary factors). Hereditary factors, for which the strongest scientific evidence exists, were endorsed as an explanation for the occurrence of the disorder less frequently than lack of willpower or broken home; only lack of parental affection and immoral lifestyle were chosen less frequently.

\section{Change in beliefs during the 1990s}

During the 1990s the most pronounced changes occurred with regard to biological causes. The percentage of those who endorsed brain disease and hereditary factors as a cause increased substantially, from $55 \%$ to $70 \%$ and from $45 \%$ to $60 \%$, respectively. With values of 0.39 , effect sizes indicated a small to medium effect. The attribution to psychosocial stress remained practically unchanged. However, the readiness to blame the individual for the illness decreased considerably. In 2001 the respondents attributed the cause less frequently to a lack of will power than 11 years before, and the same applies to the conditions under which the individual grew up, with a broken home being less frequently assumed to be a cause. In conclusion, one can state that during the 1990s the gap between mental health professionals' views on the origin of schizophrenia and public beliefs became narrower. There is a stronger tendency towards adopting the causal explanations approved of by psychiatry, whereas those that are disapproved of are more frequently rejected (Table 2).

\section{Changes in desire for social distance during the 1990s}

In sharp contrast to the changes observed with regard to the public's causal attributions was the development of the public's desire for social distance from people with schizophrenia. Rather than having decreased, as one might expect, the desire 
Table 2 Causal attributions of the population samples in 1990 and 2001

\begin{tabular}{lccccc}
\hline & $\begin{array}{c}1990 \\
(n=5 I I) \\
(\%)^{2}\end{array}$ & $\begin{array}{c}\text { 200I } \\
(n=1987) \\
(\%)^{2}\end{array}$ & Odds ratiol $(95 \% \mathrm{Cl})$ & $P$ & $\begin{array}{c}\text { Effect size } \\
\text { (absolute value) }\end{array}$ \\
\hline Brain disease & 51.0 & 70.0 & $0.443(0.333-0.592)$ & $<0.001$ & 0.387 \\
Heredity & 40.9 & 60.2 & $0.447(0.335-0.597)$ & $<0.00 \mathrm{I}$ & 0.387 \\
Life event & 73.8 & 72.3 & $1.070(0.777-1.461)$ & 0.692 & 0.032 \\
Stress at work & 62.0 & 57.7 & $1.182(0.891-1.568)$ & 0.246 & 0.086 \\
Broken home & 55.5 & 39.3 & $1.889(1.437-2.482)$ & $<0.001$ & 0.323 \\
Lack of parental affection & 36.0 & 30.4 & $1.290(0.943-1.764)$ & 0.111 & 0.119 \\
Lack of willpower & 51.6 & 36.4 & $1.838(1.394-2.424)$ & $<0.001$ & 0.308 \\
Immoral lifestyle & 18.2 & 20.9 & $0.803(0.559-1.15 \mathrm{I})$ & 0.232 & 0.070 \\
\hline
\end{tabular}

I. Logit analysis controlling for gender, age and educational attainment; reference category 200I; 510 primary sampling units.

2. Scores on points I and 2 on the five-point Likert scale ranging from 'definitely a cause' (I) to 'definitely no cause' (5) have been combined. for social distance in all social relationships studied increased markedly (Table 3). For example, whereas $19 \%$ of the respondents rejected an individual with schizophrenia as a neighbour in 1990, this number had risen to $35 \%$ in 2001 ; in 1990 about $44 \%$ would not rent a room to someone with schizophrenia but in 2001 this proportion amounted to $63 \%$.

\section{DISCUSSION}

The question implied in our introduction whether the greater the German public's endorsement of biological causes of schizophrenia the less is its desire for social distance from people with schizophrenia - has to be answered in the negative. No such relationship could be observed. On the contrary, both biological attributions and social distance were positively related with each other. Although the endorsement of biological causes increased substantially, the public's rejection of people with schizophrenia increased in the same period. To our knowledge, there exists no other study with which a direct comparison could be made. The nearest is one from the USA showing that, despite the fact that over a period of 50 years people had developed a somewhat more differentiated view of mental disorders, the stereotype of the dangerousness of the person with mental illness had increased substantially (Phelan et al, 2000).
Table 3 Social distance desired by the population samples in 1990 and 2001

\begin{tabular}{|c|c|c|c|c|c|}
\hline & $\begin{array}{c}1990 \\
(n=5 I I) \\
(\%)^{2}\end{array}$ & $\begin{array}{c}200 \mathrm{I} \\
(n=1987) \\
(\%)^{2}\end{array}$ & Odds ratio' $(95 \% \mathrm{Cl})$ & $P$ & $\begin{array}{c}\text { Effect size } \\
\text { (absolute value) }\end{array}$ \\
\hline Tenant & 43.8 & 62.9 & $0.456(0.340-0.612)$ & $<0.001$ & 0.367 \\
\hline Co-worker & 20.2 & 33.4 & $0.493(0.345-0.706)$ & $<0.00 \mathrm{I}$ & 0.303 \\
\hline Neighbour & 19.3 & 35.2 & $0.429(0.298-0.617)$ & $<0.001$ & 0.358 \\
\hline Child carer & 68.3 & 83.9 & $0.414(0.299-0.573)$ & $<0.001$ & 0.371 \\
\hline Marriage into one's family & 58.9 & 65.7 & $0.722(0.54 I-0.964)$ & 0.027 & 0.143 \\
\hline $\begin{array}{l}\text { Member of the same social } \\
\text { circle }\end{array}$ & 45.1 & 55.6 & $0.628(0.469-0.84 I)$ & 0.002 & 0.215 \\
\hline $\begin{array}{l}\text { Person one would } \\
\text { recommend for a job }\end{array}$ & 46.0 & 60.4 & $0.550(0.410-0.739)$ & $<0.001$ & 0.294 \\
\hline
\end{tabular}

I. Logit analysis controlling for gender, age and educational attainment, reference category $200 \mathrm{I}, 510$ primary sampling units.

2. Percentage of individuals who would not accept the individual in the case vignette in the specified role. Scores on points I and 2 on the five-point Likert scale ranging from 'in any case' (I) to 'in no case at all' (5) have been combined.

\section{Time trends in major depression}

The question arises as to whether our findings are specific for schizophrenia or apply to other mental disorders as well. Comparison with data for major depression derived from the same survey reveals that the changes concerning the endorsement of biological factors were here far less pronounced: in 2001, brain disease was assumed to be a cause as frequently as in 1990, and the tendency to attribute the cause to hereditary factors increased only slightly (effect size 0.15 as compared with 0.39 for schizophrenia). The desire for social distance remained virtually unchanged across all social relationships over the study period. Thus, the time trends of causal attributions and the desire for social distance with regard to major depression differed markedly from those found with schizophrenia. However, the observation that there was hardly any change of causal attributions and social distance is not inconsistent with the notion of a positive association between the two that has been observed with schizophrenia.

\section{Relationship between causal attributions and desire for social distance}

The results of our trend analysis correspond with those of cross-sectional analyses of the data from 1990 and 2001. In both surveys, an assumption that biological factors were a cause of schizophrenia was positively associated with a greater preference for social distance. Moreover, in 2001 this association was significantly stronger than in 1990. A more detailed analysis revealed that the more respondents endorsed biological factors (particularly brain disease) as a cause, the more lacking in self-control, unpredictable and dangerous they believed individuals with schizophrenia to be. This, in turn, was associated with a higher degree of fear, which resulted in a stronger desire for social distance (Dietrich et al, 2005).

\section{Societal changes and their influences on social distance}

Apart from public beliefs, other factors might have influenced people's attitudes towards those with mental illness. During the 1990s, mainly due to reunification, major societal changes took place in Germany; for example, the unemployment rate increased substantially. However, this should not have affected the public's attitudes to people with schizophrenia, 
since in our samples no significant association between the respondents' employment status and their desire for social distance could be found. Cutbacks in health services and other aspects of the welfare state, which might also have an effect on public attitudes to people with mental illness, became effective only after our second survey had been completed. In the early 1990s a number of violent acts against prominent figures had been committed in Germany by individuals who were mentally ill. Although following these incidents negative attitudes of the public to people with schizophrenia increased, they did not persist at the same level during the subsequent years. Thus, it seems unlikely that this could be responsible for the stronger desire for social distance expressed by the respondents in 2001 (Angermeyer \& Matschinger, 1996; Angermeyer \& Schulze, 2001)

\section{Implications for anti-stigma interventions}

In conclusion, one has to say that we are facing a dilemma. On the one hand, there are good reasons for improving the public's mental health literacy by informing them about the views shared by mental health professionals on the aetiology of schizophrenia, as they may have a positive effect on people's readiness to seek professional help (Angermeyer et al, 1999); on the other, promulgating biological factors as a cause of the disorder may lead to more instead of less rejection. Against the backdrop of our findings, the idea underlying some current anti-stigma programmes - namely that by educating people about biological causes of schizophrenia their attitudes will automatically improve - appears rather problematic. Our concern is that, in the end, the opposite of what was originally intended may occur.

\section{ACKNOWLEDGEMENT}

The study was funded by the German Research Association (grant AN IOI/5-I).

\section{REFERENCES}

American Psychiatric Association (1987) Diagnostic and Statistical Manual of Mental Disorders (3rd edn, revised) (DSM-III-R). Washington DC: APA.

\section{CLINICAL IMPLICATIONS}

People with schizophrenia now face more rejection than a decade ago.

- Change towards more biological causal attributions of schizophrenia is not associated with more positive attitudes towards the patients.

- Educating people about the biological causes of schizophrenia may not improve their attitudes towards people with schizophrenia.

\section{LIMITATIONS}

This is not a panel study, which would have allowed us to examine the development over time of causal attributions and the desire for social distance on an individual level.

Only the relationship between causal attributions and social distance was examined; other aspects of mental health literacy (e.g. perceived risk, treatability) and other forms of discrimination (e.g. structural discrimination) remained unconsidered.

Before our findings are generalised, they need to be replicated in other countries.

MATTHIAS C. ANGERMEYER, MD, HERBERT MATSCHINGER, PhD, Department of Psychiatry, University of Leipzig, Germany

Correspondence: Professor Dr M. C. Angermeyer, University of Leipzig, Department of Psychiatry, Johannisallee 20, D- 04317 Leipzig, Germany. Tel: +49 341 9724530; fax: +49 341 9724539; e-mail: krausem@medizin.uni-leipzig.de

(First received 18 May 2004, final revision 23 September 2004, accepted 30 September 2004)

Angermeyer, M. C. \& Matschinger, H. (1996) The effect of violent attacks by schizophrenic persons on the attitude of the public towards the mentally ill. Social Science and Medicine, 43, 1721-1728.

Angermeyer, M. C. \& Schulze, B. (2001) Reinforcing stereotypes: the focus on forensic cases in news reporting and its influence on public attitudes towards the mentally ill. International Journal of Law and Psychiatry 24, 469-486.

Angermeyer, M. C., Matschinger, H. \& RiedelHeller, S. G. (1999) Whom to ask for help in case of mental disorder? Preferences of the lay public. Social Psychiatry and Psychiatric Epidemiology, 34, 202-210.

Bogardus, E. S. (1925) Measuring social distances. Journal of Applied Sociology, 9, 299-308.

Dietrich, S., Matschinger, H. \& Angermeyer, M. C (2005) The relationship between biogenetic causal explanations and social distance toward people with mental disorders. International Journal of Social Psychiatry, in press.
Gabler, S. \& Hoffmeyer-Zlotnik, J. H. P. (1997) Stichproben in der Umfragenpraxis. Opladen: Westdeutscher Verlag.

Jorm, A. F. (2000) Mental health literacy: public knowledge and beliefs about mental disorders. British Journal of Psychiatry, 177, 396-40।

Link, B. G., Cullen, F. T., Frank, J., et al (1987) The social rejection of former mental patients: understanding why labels matter. American Journal of Sociology, 92, $146 \mid-1500$

Lopez-lbor, J. J. (2002) The WPA and the fight against stigma because of mental illness. World Psychiatry, I, 30-31.

Phelan, J. C., Link, B. G., Stueve, A., et al (2000) Public conception of mental illness in 1950 and 1996 : what is mental illness and is it to be feared? Journal of Health and Social Behavior, 4I, 188-207.

Stata (2003) Stata Statistical Software: Release 8.0 College Station, TX: Stata Corporation. 